\title{
Um estudo com professores da educação infantil e do ensino fundamental sobre suas habilidades sociais e inteligência geral
}

\section{Social Skills and general intelligence results of teachers working with elementary and kindergarten schools}

\author{
Regina Célia Cavalcante Maia \\ Mestre em Psicologia pela Universidade Gama Filho, Rio de Janeiro, RJ, Brasil
}

\section{Adriana Benevides Soares}

Professora da Universidade Salgado de Oliveira-UNIVERSO e Universidade do Estado do Rio de Janeiro-UERJ, Rio de Janeiro, RJ, Brasil

\section{Mara Sizino da Victoria}

Professora do Instituto Brasileiro de Medicina de Reabilitação-UNI-IBMR, Rio de Janeiro, RJ, Brasil

\begin{abstract}
Resumo
Este estudo buscou comparar as habilidades sociais de professores do ensino fundamental e educação infantil no Rio de Janeiro e ainda verificar as correlações entre as habilidades sociais e a inteligência. Segundo Del Prette e Del Prette (2003), as habilidades sociais devem fazer parte da formação educacional para constituir um aluno mais cooperativo e integral. Neste sentido, participaram da pesquisa 24 professores de ensino fundamental e 24 de educação infantil. Os instrumentos utilizados foram o Inventário de Habilidades Sociais (IHS - Del Prette; Del Prette, 2001a) e o Teste de Matrizes Progressivas - Raven (RAVEN, 1997). As análises estatísticas mostraram que existe uma diferença significativa nas habilidades sociais nos dois grupos de professores e que os professores da educação infantil têm escores mais altos nas habilidades sociais, confirmando a literatura sobre o assunto. As correlações entre habilidades sociais e inteligência não apresentaram significância através do teste de correlação linear Pearson, dissociando habilidades intelectuais das habilidades às situações sociais.
\end{abstract}

Palavras-chave: habilidades sociais, Inteligência geral.

\begin{abstract}
This study has compared social skills from teachers teaching in elementary and kindergarten in schools at the State of Rio de Janeiro, Brazil. It has also verified correlations between social skills and intelligence. According to Del Prette and Del Prette (2003) social skills must be part of the educational formation in order to improve student's cooperation and integration abilities. In this sense, 24 teachers
\end{abstract}


working on elementary school and 24 teachers working on kindergarten have participated in our experiment. Two instruments were used: The IHS - Inventário de Habilidades Sociais (Del Prette; Del Prette, 2001a) and Raven's Matrices (RAVEN, 1997). The statistic analyses demonstrated that there is an important difference between the two groups concerning their social skills. The teachers from kindergarten have higher social skills, as it is found at the literature about this field. The correlations between social skills and intelligence have not shown significance through the Pearson Linear Correlation Test, dissociating intellectual skills from social skills.

Keywords: Social skills, General intelligence.

\section{I ntrodução}

A escola apresenta-se como uma das mais importantes instituições sociais, por fazer, assim como outras, a mediação entre o indivíduo e a sociedade. Segundo Perrenoud (2000), a escola não deve ser pensada somente como uma formação de competências cognitivas, mas como uma preparação para a vida. Vida esta que requer o emprego de competências tanto cognitivas quanto sociais, já que o mundo do trabalho e a sociedade de uma forma geral exigem cada vez mais habilidades de interação.

Com o mundo do trabalho e da tecnologia, exigindo cada vez mais habilidades de cooperação, faz-se necessário que o professor atue de forma mais integrada e para que isto aconteça, ele próprio precisa se perceber como ser integral, social, não somente inteligente do ponto de vista acadêmico. É neste sentido que se faz necessário um repensar do papel docente, traçando estratégias que valorizem tais aspectos, utilizando as habilidades sociais nesta constituição.

Segundo Soares, Naiff, Cardozo, Baldez e Fonseca (2009) o professor é uma figura essencial para a construção dos saberes e um facilitador das potencialidades humanas. É ele quem insere o indivíduo no universo acadêmico, e é capaz de despertar o desejo pelo conhecimento e pelo desenvolvimento intelectual (COLL; COLOMINA, 1996; DEL PRETTE; DEL PRETTE; GARCIA; SILVA e PUNTEL, 1998a). A tarefa de lecionar deve apresentar a intenção de formar para além da apreensão de conteúdos e comprovação dos mesmos. O conhecimento e domínio do docente são importantes para um aproveitamento real dos alunos, porém são as relações interpessoais habilidosas aquelas capazes de potencializar este aprendizado (DEL PRETTE; DEL PRETTE, 2001b).

\section{As Habilidades Sociais (HS)}

Segundo Del Prette e Del Prette (2005), o termo habilidades sociais "aplica-se às diferentes classes de comportamentos sociais do repertório de um indivíduo, que contribuem para a competência social, favorecendo 
um relacionamento saudável e produtivo com as demais pessoas" (p. 31). Segrin e Flora (2000) apontam que as habilidades sociais estão ligadas à capacidade de um indivíduo em se comunicar e interagir com os outros de maneira efetiva e apropriada. Isso envolve um conjunto de habilidades complexas, tais como saber fazer perguntas e lidar com críticas, seguir regras, solicitar mudanças de comportamento e resolver situações interpessoais conflituosas.

Del Prette; Del Prette; Barreto; Bandeira; Rios-Saldaña; Ulian, GerkCarneiro; Falcone e Villa (2004) avaliam as habilidades sociais através de aspectos observáveis e aspectos não observáveis. Os primeiros referemse às classes comportamentais amplas como fazer e responder cumprimentos e elogios, expressar opiniões e discordâncias, iniciar, manter e encerrar conversações, fazer críticas e responder a elas. Os segundos referem-se a componentes menos amplos, verbais e nãoverbais, como de tom de voz, contato visual, gestos e a postura. Os aspectos não diretamente observáveis incluem pensamentos, percepções e representações, que precedem, acompanham ou seguem o desempenho social.

Devido a crescente complexidade das demandas sociais, tanto no nível pessoal quanto profissional, Del Prette e Del Prette ressaltam (2001a, 2003) que a escola deve se voltar para as habilidades sociais e ampliar o conceito de formação educacional, tão voltada para a capacidade cognitiva. A demanda social requer cada vez mais das pessoas habilidades sociais elaboradas. Por isso, a atuação do professor em sala de aula tem sido alvo de investigação permanente por parte dos pesquisadores da área psicológica e educacional no sentido de questionar as habilidades necessárias para suas funções. O desenvolvimento das habilidades sociais se mostra primordial na promoção de interações sociais bem sucedidas para que os alunos possam se apropriar do saber escolar.

Segundo Soares, Naiff, Cardozo, Baldez e Fonseca (2009) a importância das habilidades sociais nos professores é justificada já que a eles é incumbida à função, não só de formar profissionais, mas acima de tudo de formar cidadãos aptos a exercerem seus deveres e também requererem seus direitos em qualquer nível de ensino.

A importância de interações educativas em sala de aula é necessária para uma efetiva construção social do conhecimento. Ressaltando o papel do professor enquanto participante, condutor e mediador dessas interações, defende-se que a competência profissional do professor requer também um repertório altamente diferenciado de habilidades interpessoais que inclui, entre outros aspectos, a percepção das demandas imediatas do contexto escolar, flexibilidade para mudanças na atuação, de acordo com essas demandas, bem como habilidade de produzir conflitos sóciocognitivos entre os alunos e reagir positivamente às tentativas de solução 
destes conflitos por parte dos mesmos (DEL PRETTE; DEL PRETTE; TORRES; PONTES, 1998b).

As trocas entre professor e aluno são valorizadas, não só como experiência humana de conhecimento um do outro, mas como parte da aquisição e construção de conhecimentos acadêmicos. Portanto, a questão que se coloca é da relação entre apropriação de conhecimento por parte do aluno e as habilidades sociais dos professores no contexto escolar e discutir as particularidades dos professores de segmentos diferentes da educação.

\section{Educação Infantil e Ensino Fundamental}

Sabe-se que algumas diferenças vêm se delineando nas características exigidas dos profissionais de Educação, principalmente no que diz respeito à educação infantil. O uso do lúdico exigido neste grau de ensino prevê a utilização de metodologias agradáveis e adequadas aos alunos, atendendo aos seus interesses, faixa etária e, por conseguinte, níveis de desenvolvimento para a execução da tarefa, considerando seu aspecto global.

Percebe-se que tal fato fica muito claro quando avaliamos a seção II da Lei de Diretrizes e Bases da Educação no 9394, de 1996 em seu artigo 29 que preconiza como finalidade deste segmento, o "desenvolvimento integral da criança até seis anos de idade, em seus aspectos físico, psicológico, intelectual e social" caracterizando assim, que não apenas os aspectos diretamente ligados à aprendizagem devem estar envolvidos no processo de ensino, mas todos os aspectos que formam um ser integral (NISKIER, 1996).

Utilizando-se da brincadeira e do jogo como ferramentas de aprendizagem, podemos observar que estes proporcionam uma ação voluntária e que por si só já predispõem a criança para a aprendizagem, além de impor limites no que diz respeito a tempo, espaço e regras, também contribuindo para o espírito de criatividade, cooperação, formação da auto-estima e do autoconhecimento.

Na mesma lei em seus artigos 32 ao 36, o ensino fundamental é focado na capacidade de aprender e o ensino médio na capacidade de consolidação e aprofundamento dos conhecimentos, parecendo que nada mais precisa ser agradável e adequado ao aluno. No ensino fundamental o que se pode observar é uma priorização da chamada "parte séria" (conteúdos sistematizados do ponto de vista estritamente acadêmico) e quando se trata de ensino médio ou superior tudo fica mais sério ainda. Os aspectos de integralidade do ser, tão evocados na educação infantil, parecem ficar esquecidos; há uma ruptura, visto que não se dá 
prosseguimento ao que se postula no primeiro segmento como essencial à formação (NISKIER, 1996).

Levando-se em conta o contexto histórico do exercício do magistério no Brasil, a escola que servia apenas para as elites, teve que se universalizar, não sendo de estranhar ranços da educação tecnicista. 0 que se percebe na prática dos educadores deste segmento é que com a promulgação da LDB 9394/96, uma nova visão tem se evidenciado a partir do contexto da educação infantil, de integralização do indivíduo. A docência, que não era uma prática voltada para as diferenças individuais do corpo discente, bem como para a valorização das relações interpessoais e da diversidade de comportamentos inteligentes que vão além das áreas lingüístico-matemáticas, começa a se redefinir.

A educação atua em prol de habilidades intelectuais altamente desenvolvidas em detrimento de habilidades de contexto social. Segundo Argyle (1976), uma grande quantidade de esforço educacional é aplicado nas habilidades verbais, mas muito pouco se investe nas habilidades nãoverbais. Del Prette e Del Prette (2001b), afirmam que o contexto escolar favorece 0 desenvolvimento de habilidades como empatia, comportamento pró-social entre outras, porém, para que o aluno alcance tais habilidades, para lidar com grupos, é necessário que o professor tenha um olhar mais atento para o favorecimento de tais trocas e ele mesmo vivencie esses comportamentos.

Guerra ( $\mathrm{s} / \mathrm{d}$ ) descreve como características necessárias para o novo profissional da educação, o autoconhecimento (possibilidade de bemestar, satisfação consigo próprio); bom preparo no campo das relações interpessoais, incluída aí a afetividade.

Um trabalho realizado em Faxinal do Céu, no Paraná, através do Programa de Gestão de Educação (PROGEST) apontou que um grande número de professores apresenta dificuldades tanto na autopercepção, como na autoconsciência. Segundo o programa, há muita resistência em olhar para si mesmo e reconhecer as próprias forças propulsoras e restritivas, sendo a auto-imagem distorcida, o comportamento torna-se reativo e a motivação prejudicada com o decorrer do tempo (Guerra, s/d).

Para amenizar tais quadros, Morin (2000) propõe que os programas de formação e desenvolvimento devem auxiliar na aprendizagem de elevação da autoconsciência, da autopercepção, de abstração e criatividade, além, é claro, dos conhecimentos técnicos e teóricos.

É, portanto, com o intuito de favorecer tais práticas, que este trabalho visa ressaltar a importância de que os processos cognitivos não estejam dissociados da reflexão interpessoal, em todos os níveis de ensino, priorizando os aspectos qualitativos da educação.

Visto a importância de interações educativas para a construção social do conhecimento em sala de aula e considerando as diferenças entre os professores de educação infantil e ensino fundamental, este trabalho 
investiga se os professores de educação infantil apresentam maiores escores em habilidades sociais que os professores do ensino fundamental. Nossa hipótese se fundamenta no fato de que os professores de educação infantil são exigidos na sua prática não apenas aspectos diretamente ligados à aprendizagem formal, mas também aspectos relacionados às situações sociais. O estudo das habilidades sociais no âmbito da escola é fundamental porque defende que a competência profissional do professor requer, além de conhecimento acadêmico, um repertório diferenciado de habilidades interpessoais que inclui, entre outros aspectos, a percepção das demandas imediatas do contexto escolar e flexibilidade para mudanças na atuação, de acordo com essas demandas. Um estudo de Del Prette e Del Prette (1995) mostra que, embora os professores relatem a emissão de resposta indicativa de um repertório suficiente de habilidades sociais cotidianas e valorizem configurações interativas à construção de conhecimento, na maioria das vezes na sua prática, reserva ao aluno um papel passivo e assimilador. Assim, ao se considerar as relações interpessoais como fundamentais para o desenvolvimento e a aprendizagem em contexto escolar faz-se necessário avaliar o repertório de habilidades sociais dos professores destes dois segmentos.

Além disso, como foco secundário, este trabalho busca analisar as correlações entre as habilidades sociais e a inteligência geral ou capacidade cognitiva geral, como uma capacidade mental que envolve, entre outras coisas, a habilidade de raciocinar, planejar, resolver problemas, pensar abstratamente, aprender com a experiência, sendo, portanto, um construto extremamente relacionado ao alcance de conquistas acadêmicas, pessoais e profissionais (LUBINSKI, 2004). As correlações entre habilidades sociais e inteligência geral nos dois grupos de professores procuram reavivar as discussões sobre os aspectos acadêmicos e sociais.

\section{I-Método}

\section{Participantes}

Participaram deste estudo 24 professores da Educação Infantil e 24 do Ensino Fundamental de escolas privadas e públicas do Rio de Janeiro.

\section{Instrumentos}

Foram dois os instrumentos utilizados: o Inventário de Habilidades Sociais e o Teste de Matrizes Progressivas - Raven.

1 - Teste de Matrizes Progressivas - Raven

Foi utilizado o Teste de Matrizes Progressivas séries A, B, C, D e E de Raven (1997). 
Constitui-se de 60 itens divididos em cinco séries: A, B, C, D e E, com 12 itens cada um. Cada item possui uma matriz composta de figuras geométricas abstratas em preto e branco com uma lacuna a ser preenchida. Abaixo da matriz há de 6 a 8 figuras, sendo que apenas uma delas completa corretamente a matriz. Os primeiros itens de cada série são bastante simples e vão crescendo em dificuldade.

2 - Inventário de Habilidades Sociais (IHS)

O Inventário de Habilidades Sociais é um instrumento de auto-relato utilizado para aferir o repertório de habilidades sociais a partir de amostras de situações interpessoais cotidianas (Del Prette; Del Prette, 2001a).

Composto de trinta e oito itens que descrevem situações sociais em vários contextos, o instrumento permite uma identificação inicial das classes e subclasses de habilidades sociais que podem ser caracterizadas como disponíveis ou deficitárias no repertório do respondente, envolvendo contextos de trabalho, lazer e família. Contemplam também diferentes tipos de interlocutores como colegas, familiares e superiores, bem como habilidades diversas, entre as quais estão: falar em público, expressar sentimento e pedir mudança de comportamento.

Nas instruções de preenchimento do IHS solicita-se que o respondente estime a freqüência com que reage da forma sugerida em cada item. A escala utilizada é a do tipo Likert com 5 pontos que varia de nunca ou raramente a sempre ou quase sempre, para que o respondente assinale a freqüência com que reage da forma apresentada em cada item. Parte dos itens é redigida de modo negativo, ou seja, com freqüência mais elevada na reação que indica déficit na habilidade relacionada aquela situação. Estes são: 2, 8, 9, 13, 17, 18, 19, 22, 23, 24, 26, 34, 36 e 37, onde a pontuação dos escores é invertida.

Os cinco fatores avaliados no inventário são descritos da seguinte forma:

Fator 1 - denominado enfrentamento com risco - reúne 11 itens que retratam situações interpessoais em que a demanda de reação do interlocutor caracteriza-se pela afirmação e defesa de direitos e de autoestima, com risco potencial de reação indesejável por parte do interlocutor.

Fator 2 - denominado auto-afirmação na expressão de afeto positivo retrata demandas interpessoais de expressão de afeto positivo e de afirmação da auto-estima, com risco mínimo de reação indesejável. Composto por 7 itens.

Fator 3 - conversação e desenvoltura social - demanda traquejo social na conversação o que supõe conhecimento das normas de relacionamento cotidiano. Compõe-se de 7 itens.

Fator 4 - auto-exposição a desconhecidos ou a situações novas - inclui situações que envolvem abordagem a pessoas desconhecidas e compõese de 4 itens. 
Fator 5 - autocontrole da agressividade a situações aversivas - demanda controle de raiva e agressividade. Composto de 3 itens.

Ressalta-se que há 7 itens que não se relacionam com nenhum fator. São eles: $33,02,25,27,32,34$ e 04.

$\mathrm{Na}$ análise de consistência interna do IHS foi obtido um coeficiente Alpha de Cronbach de 0,75 que pode ser considerado satisfatório, de acordo com a meta-análise de Del Prette e Del Prette (2001a), permitindo assim, atribuir validade de construto ao IHS.

\section{Procedimentos}

Foram apresentados os testes Matrizes Progressivas (Raven) e Inventário de Habilidades Sociais (IHS), nesta ordem respectivamente, explicando a forma de preenchimento. Os testes foram respondidos pelos sujeitos em tempo livre. Após seu término os mesmos foram recolhidos pelo pesquisador para análise estatística.

\section{[ I I - Resultados}

1- Média e Desvio Padrão da Amostra

Participaram desta pesquisa 48 professores, todos do sexo feminino, sendo 24 da educação infantil e 24 do ensino fundamental (12 de instituições públicas e 12 de instituições privadas do Rio de Janeiro). A média da idade dos sujeitos foi de 34,98 (desvio padrão de 8,34 ).

2- Análise do Raven

Tabela 1

Distribuição do Raven

Educação Infantil e no Ensino Fundamental

\begin{tabular}{c|c|c|c|c|c}
\hline Nível de Ensino & N & Média & $\begin{array}{l}\text { Desvio } \\
\text { Padrão }\end{array}$ & t & p \\
\cline { 1 - 4 } Educação Infantil & 24 & 49,00 & 4,39367 & \multirow{2}{*}{0,095} & 0,924 \\
\cline { 1 - 3 } Ensino Fundamental & 24 & 48,87 & 4,68404 & & \\
\hline
\end{tabular}

Os resultados expressos na Tabela 1 indicam que a diferença nos escores obtidos pelos professores da educação infantil e ensino fundamental na escala de Raven não é significativa $(t=0,095$ e $p=0,924)$. Ambos apresentam classificação média nos níveis de descrição dos resultados do Raven, o que torna os grupos homogêneos nesta variável.

3- Análise do IHS

Para avaliar a hipótese de que os professores da educação infantil apresentam maiores escores em habilidades sociais do que os professores 
do ensino fundamental, utilizou-se o teste t para amostras independentes, com o objetivo de comparar os escores obtidos por estes no IHS.

Tabela 2

Comparação dos Professores de Educaçẫo Infantil e Ensino Fundamental em Habilidades Sociais Segmentados por Fator

\begin{tabular}{|c|c|c|c|c|c|c|}
\hline Variáveis & Nivel Ensino & $N$ & Média & $\begin{array}{l}\text { Desuio } \\
\text { Padrão }\end{array}$ & $\mathbf{t}$ & $\mathbf{p}$ \\
\hline \multirow[b]{2}{*}{ IHStotalPtos } & Educação Infantil & 24 & 105,75 & 15,05 & \multirow[b]{2}{*}{2,657} & \multirow[b]{2}{*}{$0,011^{*}$} \\
\hline & $\begin{array}{l}\text { Ensino } \\
\text { Fundamental }\end{array}$ & 24 & 94,87 & 13,25 & & \\
\hline \multirow[b]{2}{*}{ IHSFator1 } & Educação Infantil & 24 & 10,77 & 3,07 & \multirow[b]{2}{*}{2,355} & \multirow[b]{2}{*}{$0,023^{* *}$} \\
\hline & $\begin{array}{l}\text { Ensino } \\
\text { Fundamental }\end{array}$ & 24 & 8,89 & 2,41 & & \\
\hline \multirow[b]{2}{*}{ IHSFator2 } & Educação Infantil & 24 & 10,40 & 1,01 & \multirow[b]{2}{*}{1,871} & \multirow[b]{2}{*}{0,068} \\
\hline & $\begin{array}{l}\text { Ensino } \\
\text { Fundamental }\end{array}$ & 24 & 9,74 & 1,38 & & \\
\hline \multirow[b]{2}{*}{ IHSFator3 } & Educação Infantil & 24 & 7,42 & 1,59 & \multirow[b]{2}{*}{1,095} & \multirow[b]{2}{*}{0,279} \\
\hline & $\begin{array}{l}\text { Ensino } \\
\text { Fundamental }\end{array}$ & 24 & 6,84 & 2,04 & & \\
\hline \multirow[b]{2}{*}{ IHSFator4 } & Educação Infantil & 24 & 3,83 & 1,88 & \multirow[b]{2}{*}{1,765} & \multirow[b]{2}{*}{0,084} \\
\hline & $\begin{array}{l}\text { Ensino } \\
\text { Fundamental }\end{array}$ & 23 & 3,04 & 1,09 & & \\
\hline \multirow[b]{2}{*}{ IHSFator5 } & Educação Infantil & 24 & 1,02 & 0,48 & \multirow[b]{2}{*}{0,357} & \multirow[b]{2}{*}{0,723} \\
\hline & $\begin{array}{l}\text { Ensino } \\
\text { Fundamental }\end{array}$ & 24 & 0,95 & 0,76 & & \\
\hline
\end{tabular}

* Significativo ao nível de $0,01 * *$ Significativo ao nível de 0,05

Os resultados da Tabela 2 indicam que a diferença entre os professores da educação infantil e do ensino fundamental é significativa nos escores obtidos em IHS total ( $t=2,657$ e $p=0,011$ ) sendo, portanto, corroborada a hipótese acima citada. Observe-se ainda que o IHS fator 1 também apresentou resultado significativo na diferença entre os professores da educação infantil e ensino fundamental ( $t=2,335$ e $p=0,023)$.

4- Discriminação por Repertório de Habilidades Sociais Apresentar-se-á um levantamento discriminado por repertórios de habilidades sociais, visando facilitar uma análise mais apurada desta amostra. A educação infantil destacou-se não somente no escore geral, mas também nos fatores 1, 2, 3 e 4 (conforme Tabela 3). 
Tabela 3

Discriminaçẫo dos Repertórios por Grupos

\begin{tabular}{|c|c|c|c|c|c|c|c|c|c|c|c|c|c|}
\hline & Rep & E T & $\%$ & F1 & $\%$ & F2 & $\%$ & F3 & $\%$ & F4 & $\%$ & F5 & $\%$ \\
\hline $\begin{array}{c}\text { Ensino } \\
\text { Fundamental }\end{array}$ & $\begin{array}{c}\text { RBE } \\
\text { BAC } \\
\text { BAB } \\
\text { TR }\end{array}$ & $\begin{array}{l}6 \\
9 \\
6 \\
3\end{array}$ & $\begin{array}{l}25,0 \\
\mathbf{3 7}, 5 \\
25,0 \\
12,5\end{array}$ & $\begin{array}{c}4 \\
10 \\
7 \\
3\end{array}$ & $\begin{array}{l}16,7 \\
41,7 \\
29,1 \\
12,5\end{array}$ & $\begin{array}{l}8 \\
7 \\
4 \\
5\end{array}$ & $\begin{array}{l}33,3 \\
29,1 \\
16,7 \\
20,9\end{array}$ & $\begin{array}{c}10 \\
3 \\
2 \\
9\end{array}$ & $\begin{array}{c}41,7 \\
12,5 \\
8,3 \\
37,5\end{array}$ & $\begin{array}{l}2 \\
9 \\
5 \\
8\end{array}$ & $\begin{array}{c}8,3 \\
37,5 \\
20,9 \\
33,3\end{array}$ & $\begin{array}{l}2 \\
9 \\
8 \\
5\end{array}$ & $\begin{array}{c}8,3 \\
37,5 \\
33,3 \\
20,9\end{array}$ \\
\hline $\begin{array}{c}\text { Educação } \\
\text { Infantil }\end{array}$ & $\begin{array}{c}\text { RBE } \\
\text { BAC } \\
\text { BAB } \\
\text { TR }\end{array}$ & $\begin{array}{c}13 \\
7 \\
2 \\
2 \\
\end{array}$ & $\begin{array}{c}\mathbf{5 4 , 3} \\
29,1 \\
8,3 \\
8,3 \\
\end{array}$ & $\begin{array}{c}10 \\
11 \\
1 \\
2 \\
\end{array}$ & $\begin{array}{c}41,7 \\
45,8 \\
4,2 \\
8,3 \\
\end{array}$ & $\begin{array}{c}11 \\
9 \\
4 \\
- \\
\end{array}$ & $\begin{array}{c}\mathbf{4 5 , 8} \\
37,5 \\
16,7 \\
- \\
\end{array}$ & $\begin{array}{c}13 \\
3 \\
3 \\
5 \\
\end{array}$ & $\begin{array}{l}\mathbf{5 4 , 2} \\
12,5 \\
12,5 \\
20,8 \\
\end{array}$ & $\begin{array}{c}10 \\
5 \\
5 \\
4 \\
\end{array}$ & $\begin{array}{l}41,6 \\
20,8 \\
20,8 \\
16,6 \\
\end{array}$ & $\begin{array}{l}3 \\
7 \\
7 \\
7\end{array}$ & $\begin{array}{l}12,5 \\
29,1 \\
29,1 \\
29,1\end{array}$ \\
\hline Total & & 48 & 100 & 48 & 100 & 48 & 100 & 48 & 100 & 48 & 100 & 48 & 100 \\
\hline
\end{tabular}

Freqüências maiores em negrito

Legenda

\begin{tabular}{|l|l|}
\hline ET & Escore total \\
\hline RBE & $\begin{array}{l}\text { Repertório bastante elaborado } \\
\text { de habilidades sociais }\end{array}$ \\
\hline BAC & $\begin{array}{l}\text { Bom repertório de habilidades } \\
\text { sociais acima da mediana }\end{array}$ \\
\hline BAB & $\begin{array}{l}\text { Bom repertório de habilidades } \\
\text { sociais abaixo da mediana }\end{array}$ \\
\hline TR & $\begin{array}{l}\text { Indicacao para treinamento em } \\
\text { habilidades sociais }\end{array}$ \\
\hline
\end{tabular}

O ensino fundamental contemplou os fatores 1,2 e 3, ficando excluído de seu repertório os fatores 4 e 5 .

$\mathrm{Na}$ observação dos repertórios discriminados por segmentos, conclui-se que os professores de educação infantil destacam-se em quase todos os fatores contemplados por esta amostra. No escore total, a diferença se faz ainda maior, sendo freq $=20$ nos repertórios acima da mediana na educação infantil e freq=15 no ensino fundamental. $O$ fator onde este segmento obteve melhor escore foi o fator 3 (conversação e desenvoltura social), com freq $=13$, se considerado apenas o repertório bastante elaborado. Somando-se as freqüências dos repertórios bastante elaborado e bom acima da mediana, em todos os fatores este segmento manteve-se com freqüência acima da mediana, ( $F 1$ com freq $=21$; F2 com freq=20 e F4 com freq=15) com exceção apenas do fator 5 (autocontrole da agressividade), que obteve freqüência abaixo da mediana nos dois segmentos.

No escore total de habilidades sociais o ensino fundamental obteve freqüência 6 no repertório bastante elaborado e 9 no repertório bom acima da média. No fator 1 (enfrentamento com risco) 4 foi a freqüência no repertório bastante elaborado e 9 no repertório bom acima da mediana. No fator 3 (conversação e desenvoltura social) a freqüência foi 10 no repertório bastante elaborado e 3 no repertório bom acima da mediana. 
5- Análise das Correlações: habilidades sociais e inteligência

Para verificar as correlações entre estes dois construtos nos dois segmentos da educação foi utilizado o teste de correlação linear Pearson, nas Tabelas 4 e 5.

\section{Tabela 4}

Correlações IHS e Raven na amostra total

\begin{tabular}{l|l|l}
\cline { 2 - 3 } & \multicolumn{2}{|l}{ RavenPtos } \\
\cline { 2 - 3 } & $\mathrm{r}$ & $\mathrm{p}$ \\
\hline IHStotalPtos & 0,086 & 0,561 \\
\hline IHSFator1 & 0,011 & 0,939 \\
\hline IHSFator2 & 0,025 & 0,864 \\
\hline IHSFator3 & 0,067 & 0,649 \\
\hline IHSFator4 & 0,245 & 0,097 \\
\hline IHSFator5 & $-0,160$ & 0,278 \\
\hline
\end{tabular}

Tabela 5

Correlaçốes IHS e Raven:

Educação Infantil e Ensino Fundamental

\begin{tabular}{l|l|c|c|c} 
& \multicolumn{4}{c}{ RavenPtos } \\
\cline { 2 - 5 } & \multicolumn{2}{c}{$\begin{array}{c}\text { Educação } \\
\text { Infantil }\end{array}$} & \multicolumn{2}{c}{$\begin{array}{c}\text { Ensino } \\
\text { Fundamental }\end{array}$} \\
\cline { 2 - 5 } & $r$ & $p$ & $r$ & $p$ \\
\hline IHStotalPtos & 0,034 & 0,874 & 0,144 & 0,502 \\
\hline IHSFator1 & $-0,012$ & 0,956 & 0,030 & 0,889 \\
\hline IHSFator2 & $-0,102$ & 0,634 & 0,109 & 0,613 \\
\hline IHSFator3 & 0,186 & 0,385 & $-0,020$ & 0,925 \\
\hline IHSFator4 & 0,296 & 0,161 & 0,201 & 0,357 \\
\hline IHSFator5 & $-0,223$ & 0,295 & $-0,129$ & 0,548 \\
\hline
\end{tabular}

Observa-se que nenhuma das correlações apresentou significância, portanto não há correlação entre estes construtos. Com base nos dados coletados, pode-se concluir que os fatores $1,2,3$ e 4 compõem o repertório de habilidades sociais dos professores da educação infantil. Sendo as maiores freqüências apresentadas no fator 1 (enfrentamento com risco), no escore geral e no fator 3 (conversação e desenvoltura social). Note-se que existe uma dificuldade no repertório de habilidades sociais do fator 5 (autocontrole da agressividade).

O ensino fundamental, com pontuações inferiores às pontuações da educação infantil, apresentou como componentes de seu repertório de 
habilidades sociais, os fatores 1 e $3 \mathrm{com}$ as maiores freqüências e o fator 2 (auto-afirmação na expressão de sentimento positivo) com menor freqüência. Os fatores 4 (auto-exposição a desconhecidos) e 5 (autocontrole da agressividade) não compõem o repertório de habilidades sociais dos professores deste segmento na amostra estudada. Registra-se baixos escores nos professores do ensino fundamental no fator 4 . Numa revisão de literatura, observa-se que Xisto (2000) também encontrou baixos escores no repertório de habilidades sociais no seu grupo amostral neste fator, podendo ser este fato, fonte de pesquisas futuras, ressaltando porém, que a educação infantil não apresentou tais escores.

No fator 5 (autocontrole da agressividade), o repertório de habilidades sociais dos professores dos dois grupos ficou abaixo da mediana, chamando a atenção o fato de que em estudos recentes com estudantes de Psicologia de vários estados brasileiros foram encontraram resultados semelhantes (DEL PRETTE, DEL PRETTE; BARRETO; BANDEIRA; RIOSSALDAÑA; ULIAN; GERK-CARNEIRO; FALCONE; VILLA, 2004).

Caballo (1993) relata que estudos mostram mulheres como mais habilidosas na expressão de sentimentos positivos e homens na expressão de sentimentos negativos. Como a amostra deste estudo é composta em sua totalidade pelo público feminino, os dados encontrados devem ser considerados em apoio aos resultados encontrados por Caballo.

Nas pesquisas, tanto de Xisto (2000) quanto de Cavalieri (2002) foram encontrados baixos escores no repertório dos professores do ensino superior e médio no fator 3 , sugerindo pesquisas futuras considerando este fato. Contudo, ressalta-se aqui que isto não ocorreu nos grupos desta pesquisa, tendo, pelo contrário, pontuado bem neste fator, principalmente a educação infantil.

Para concluir, os resultados mostram que na apuração dos itens mais freqüentes desta amostra foi encontrado: no ensino fundamental, fator 1 (21 e 29), fator 2 (todos os itens- 03, 08, 28, 35, 30, 06 e 10), fator 3 (17 e 37) e fator 5 (38 e 18). Na educação infantil, fator $1(21,16,15$ e 29), fator 2 (todos os itens), fator 3 (17, 37 e 24), fator 4 (23 e 26) e fator 5 (38 e 18). Os itens que obtiveram pontuações mais altas no ensino fundamental foram $(03,28$ e 35$)$ todos do fator 2 , e na educação infantil $(03,28,08$ e 06$)$ no fator 2 e (21) no fator 1 .

\section{IV- Discussão}

Através dos resultados pode-se corroborar a primeira questão deste estudo, a de que os professores da educação infantil apresentariam maiores escores de habilidades sociais que os professores do ensino fundamental. Incluindo-se ainda ao estudo, uma comparação com estudos anteriores (XISTO, 2000; CAVALIERI, 2002) que reafirmam a 
apresentação de repertórios mais elaborados na educação infantil, quando comparados aos professores dos outros segmentos de ensino.

A partir destes dados, não há como negar o caráter próprio da educação infantil. Acredita-se que este fato seja facilitado pelo contexto evocado neste segmento, de valorização do ser integral, de manipulação, de valorização das relações interpessoais que começam a se delinear e de ludicidade, evidenciados na Lei 9394/96, exigindo do profissional que atende a esta faixa etária, uma postura mais voltada para as demandas das crianças e seus familiares, facilitando assim, um repertório mais apurado de habilidades sociais. Este trabalho buscou esta reflexão, ressaltando que a aprendizagem dos aspectos formais é precedida pelas relações interpessoais. Vigotski (2000) já retratava a importância destas relações no desenvolvimento humano quando dizia que o outro é um parceiro perpétuo na vida psíquica. Assim considerado, é na relação com o outro que se constrói cada ser. Portanto, não há como fazer educação sem priorizar tais habilidades sociais.

Vigotski (2000) afirma ainda que a qualidade das relações que as crianças são expostas mapeia as diferentes realidades por ela assimiladas e, simultaneamente, os tipos de indivíduos construídos por essa realidade, influenciando o processo e o conteúdo do desenvolvimento de suas características pessoais (modo de agir e pensar) e as concepções do mundo (CAMPOS; DEL PRETTE; DEL PRETTE, 2000). Portanto, se o professor for preparado para práticas que visem desenvolver habilidades relacionais, pode estar prevenindo vários problemas dos alunos. Estudos comprovam que a intervenção em problemas interpessoais pode influenciar positivamente, inclusive em dificuldades de aprendizagem (Murta, 2005).

Neste sentido, a escola deve investir mais na área de habilidades sociais para que se façam relações mais saudáveis, ampliando de fato, o conceito de formação para a vida, enfatizado na educação vigente.

Em relação à segunda questão, a análise das correlações entre as habilidades sociais e a inteligência nos dois grupos de professores, os dados não se mostraram significativos. Na análise do Raven, os professores de educação infantil e ensino fundamental apresentaram classificação média nos níveis de descrição e, por isso, independentemente da sua prática profissional, os grupos eram homogêneos. Portanto, apesar dos professores do ensino fundamental privilegiarem o desenvolvimento de conteúdos sistematizados, como os aspectos intelectuais, eles não eram diferentes do ponto de vista da inteligência, se comparado aos professores de educação infantil. Isso mostra que, mesmo os professores de ambos os grupos terem um nível de inteligência estatisticamente semelhante, os professores de educação infantil privilegiam as habilidades sociais e têm uma prática mais ampla e rica que os professores de ensino fundamental. 
A ausência de correlação entre inteligência geral e habilidades sociais mostra as características de cada constructo, como variáveis independentes em certo grau. O Teste de Matrizes Progressivas de Raven é um teste de inteligência geral em que estão envolvidas avaliações de figuras que exige um padrão lógico, onde o objetivo não se aproxima em nada com a avaliação das relações interpessoais. O conceito de habilidades sociais é mais amplo porque aponta para uma repercussão no rendimento da capacidade cognitiva pessoal e interacional, embora não haja uma relação direta entre habilidades sociais e capacidade cognitiva (DEL PRETTE; DEL PRETTE, 2005). Portanto, conceitualmente ambas variáveis não seriam diretamente correlacionadas e os dados corroboram isso. O questionamento maior que se pode levantar é sobre o que a escola prioriza como habilidade primordial no exercício de ser professor. Os valores atribuídos ao professor provavelmente seriam aqueles atribuídos ao que a escola também prioriza em relação ao aluno. A intenção do estudo sobre as habilidades sociais dos professores e a inteligência geral é de ampliar o questionamento acerca das características de um professor, a influência destas características na apropriação do saber por parte do aluno e na concepção que a escola tem das necessidades inerentes ao processo de aprendizagem.

Estes resultados demonstram que a escola precisa estender seu conceito de educação, de uma educação que enfoca habilidades intelectuais altamente desenvolvidas para uma educação que, além da preocupação com os aspectos intelectuais, desenvolva habilidades às situações sociais, habilidades essas que são cada vez mais exigidas tanto no nível profissional como no pessoal nos dias de hoje (Bandeira; COSTA; DEL PRETTE; DEL PRETTE; DEL PRETTE e GERK-CARNEIRO, 2000).

\section{Referências Bibliográficas}

Argyle, M. A interação social: relações interpessoais e comportamento social. Rio de Janeiro: 1976. Bandeira, M.; COSTA, M. N.; DEL PRETTE, Z. A. P.; DEL PRETTE, A.; GERK-CARNEIRO, E. Qualidades psicométricas do Inventário de Habilidades Sociais (IHS): estudo sobre a estabilidade temporal e validade concomitante. Estudos de Psicologia, Natal, v. 5, n. 2, p. 401-419, 2000.

Caballo, V. E. Manual de Entrenamiento y evolucion de las habilidades sociales. Madrid: Siglo Veintiuno, 1993.

Campos, T. N.; Del Prette Z. A. P.; Del Prette, A. (Sobre)vivendo nas ruas: habilidades sociais e valores de crianças e adolescentes.Psicologia:

Reflexão e Crítica, Porto Alegre, v. 13, n. 3, p. 517-527, 2000. 
Cavalieri, A. M. Inteligência interpessoal de professores: um estudo exploratório. 2002. 123 f. Dissertação (Mestrado em Psicologia), Instituto de Psicologia, Universidade Gama Filho, Rio de Janeiro.

Coll, C.; Colomina, R. Interação entre alunos e aprendizagem escolar. In: COLL, C. (Org.) Desenvolvimento psicológico e educação: psicologia da educação. Tradução de Angélica Mello Alves. Porto Alegre: Artes Médicas, 1996. p. 298-311.

DEL PRETTE, Z. A. P.DEL PRETTE, A.; GARCIA, F. A.; SILVA, A. T. B.; PUNTEL, L. P. Habilidades sociais do professor em sala de aula: um estudo de caso. Psicologia: Reflexão e Crítica, Porto Alegre, v. 11, n. 3, p. 591-603, 1998a.

DEL PReTte, A.; DEL PReTte, Z. A. P.; TORRES, A. C.; PONTES, A. C. Efeitos de uma intervenção sobre a topografia das habilidades sociais de professores. Psicologia Escolar e Educacional, Itatiba, v.2, n.1, p.1122, 1998b.

Del Prette, Z. A. P.; Del Prette, A. Interações sociais em sala de aula: representações do professor. In: GUZZO, R. G. P.; WITTER, S.; PFROMM NETTO, E.; ROSADO, G.; WECHSLER, S. (Orgs.). O futuro da criança na escola, família e sociedade. São Paulo: Átomo, 1995, p. 426-430.

Del Prette, Z. A. P.; Del Prette, A. Inventário de Habilidades Sociais (IHS-Del Prette): manual de aplicação, apuração e interpretação. São Paulo: Casa do Psicólogo, 2001a.

Del Prette, Z. A. P.; Del Prette, A. Psicologia das relações interpessoais: vivências para o trabalho de grupo. Petrópolis: Vozes, 2001b.

Del Prette, Z. A. P.; Del Prette, A. Habilidades, desenvolvimento e aprendizagem: questões conceituais, avaliação e intervenção. São Paulo: Alínea, 2003.

Del Prette, Z. A. P.; DEL PRETTE, A. BARRETO, M. C. M.; BANDEIRA, M.; RIOS-SALDAÑA, M. R.; ULIAN, A. L. A. O.; GERK-CARNEIRO, E.; FALCONE, E. M. O.; VILLA, M. B. Habilidades sociais de estudantes de Psicologia: um estudo multicêntrico. Psicologia: Reflexão e Crítica, Porto Alegre, v. 17, n. 3, p. 341-350, 2004.

Del Prette, Z. A. P.; Del Prette, A. Psicologia das habilidades sociais na infância. Petrópolis, RJ: Vozes, 2005.

Guerra, M. K. Desafios e perspectivas da educação. Disponível em: http://www.googleacademico.com.br/inteligencia/educação?artigos/in dex.htm. Acesso em: 12 julho 2006, s/d.

Lubinski, D. Introduction to the special section on cognitive abilities: 100 years after Spearman's - 1904 - General Intelligence, Objectively Determined and Measured. Journal of Personality and Social Psychology, Washington, v. 86, n.1, p. 96-111, 2004.

Morin, E. Os sete saberes necessários à educação do futuro. São Paulo: Cortez, 2000. 
Murta, S. G. Aplicações do treinamento em habilidades sociais: análise da produção nacional. Psicologia: Reflexão e Crítica, Porto Alegre, v. 18, n. 2, p. 283-291, 2005.

Niskier, A. LDB: a nova lei da educação - tudo sobre a nova lei de diretrizes e bases da educação nacional - uma visão crítica. Rio de Janeiro: Consultor, 1996.

Perrenoud, P. H. Dez novas competências para ensinar. Porto Alegre: Artmed, 2000.

RAVEN, J. C. Matrizes Progressivas - Escala Geral. Rio de Janeiro: CEPA, 1997.

Segrin, C.; Flora, J. Poor social skills are a vulnerability factor in the development of psychosocial problems. Human Communication Research, Massachussets, v. 26, n. 3, p. 489-514, 2000.

Soares, A. B.; NAIFF, L.; CARDOZO, A.; BALDEZ, M.; FONSECA, L. As habilidades sociais e variáveis sócio-demográficas de professores.Psicologia: Teoria e Prática, São Paulo, v. 11, n. 1, no prelo, 2009.

VIGOTSKI, L. S. Manuscrito de 1929. Educação e Sociedade, Campinas, v. 21, n. 71, p. 21-44, 2000.

Xisto, S. M. S. Professor universitário: inteligente ou habilidoso? 2000. 89 f. Dissertação (Mestrado em Psicologia), Instituto de Psicologia, Universidade Gama Filho, Rio de Janeiro.

\section{Endereço para correspondência}

Regina Célia Cavalcante Maia

Prefeitura de São J oão de Meriti, Av. Presidente Lincoln, 899, Vilar dos Teles, São J oão de Meriti, Rio de Janeiro, RJ, Brasil. CEP: 20555-201.

Endereço eletrônico: rccmaia@ig.com.br

Adriana Benevides Soares

Universidade do Estado do Rio de Janeiro-UERJ, Rua São Francisco Xavier, 524, Bloco F,

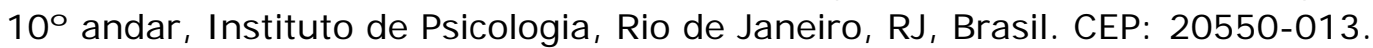

Endereço eletrônico: adribenevides@gmail.com

Mara Sizino da Victória

Instituto Brasileiro de Medicina de Reabilitação, Praia de Botafogo, 158-160, Botafogo, Rio de Janeiro, RJ, Brasil. CEP: 22250-040

Endereço eletrônico: marasizino@yahoo.com.br

Recebido em: 01/10/2008

Aceito para publicação em: 06/07/2009

Editor responsável: Deise Mancebo 